\title{
Caracterização Química das Plantas aquáticas Coletadas no RESERVATÓRIO DE SALTO GRANDE (AMERICANA-SP) ${ }^{1}$
}

\author{
Chemical Characterization of Aquatic Plants Assessed in Salto Grande Reservoir \\ (Americana-SP, Brazil)
}

\begin{abstract}
MARTINS, D. ${ }^{2}$, COSTA, N.V. ${ }^{3}$, TERRA, M.A. ${ }^{3}$, MARCHI, S.R. ${ }^{3}$ e VELINI, E.D. ${ }^{2}$
RESUMO - O objetivo deste trabalho foi caracterizar a constituição química das espécies de plantas aquáticas Brachiaria arrecta, Eichhornia crassipes, Pistia stratiotes e Salvinia auriculata - encontradas no reservatório da usina hidrelétrica de Salto Grande, em Americana-SP - de forma a fornecer subsídios para futuras avaliações sobre o comportamento da biomassa dessas espécies em local de descarte ou no próprio reservatório. As amostras de plantas foram coletadas no dia 16.4.2002, sendo desidratadas em estufa de circulação forçada de ar a $60{ }^{\circ} \mathrm{C}$. B. arrecta apresentou os menores teores médios de macro e micronutrientes e o maior teor médio de elementos pesados na matéria seca, em relação às demais espécies. A relação C/N das espécies E. crassipes, $P$. stratiotes e $S$. auriculata apresentou valores próximos. Não foi detectada, em nenhuma das espécies estudadas, a presença dos elementos molibdênio, prata, chumbo e mercúrio.
\end{abstract}

Palavras-chave: planta daninha, macrófitas aquáticas, nutrientes.

ABSTRACT - This research aimed to describe the chemical components of the following aquatic plants: Brachiaria arrecta, Eichhornia crassipes, Pistia stratiotes and Salvinia auriculata, found in a reservoir formed by Salto Grande power plant in Americana-SP, Brazil, to provide a basis for future evaluations of the biomass behavior of these species at waste points or in the reservoir. Plant samples were collected on 04/16/2002. B. arrecta showed the lowest medium contents of macro and micronutrients and the highest medium contents of heavy metal in the dry matter, compared to the other aquatic species. The $C / N$ relationship of E. crassipes, $\boldsymbol{P}$. stratiotes and $\mathbf{S}$. auriculata showed similar contents. Molybdenum, silver, lead and mercury were not detected in any of the species studied.

Key words: weed, aquatic macrophytes, and nutrients.

\section{INTRODUÇÃO}

A construção de barragens destaca-se como uma atividade importante, uma vez que os grandes reservatórios formados fornecem água para o consumo da população urbana, para a produção agrícola e industrial, bem como para a geração de energia elétrica. No entanto, a interferência antrópica - realizada sem planejamento e de maneira arbitrária em ambientes aquáticos - afeta a estrutura dos habitats existentes, alterando substancialmente o equilíbrio do ecossistema e promovendo redução ou incremento da heterogeneidade das assembléias de macrófitas aquáticas no novo ambiente formado (Thomaz, 2002; Moraes, 1999).

O carreamento de fertilizantes aplicados em áreas de atividades agrícolas e agropecuárias, no sentido de pequenos cursos d’água, riachos, lagos ou lagoas e reservatórios

1 Recebido para publicação em 18.12.2002 e na forma revisada em 26.3.2003.

2 Prof. Dr., Dep. Produção Vegetal/Agricultura da Faculdade de Ciências Agronômicas - FCA-UNESP, Caixa Postal 237, 18603-970 Botucatu-SP, <dago@fca.unesp.br>; ${ }^{3}$ Eng.-Agr., aluno de pós-graduação, Dep. de Produção Vegetal - FCA-UNESP. 
artificiais, além da descarga de efluentes residenciais e industriais, leva esses ambientes a uma condição de eutrofização, podendo contribuir com crescimento acelerado e descontrolado da comunidade de plantas aquáticas presentes.

O processo de eutrofização dos sistemas aquáticos pode acarretar diversos prejuízos à atividade pesqueira, à saúde pública, aos esportes náuticos e ao turismo, além do entupimento das grades de tomadas d'água das turbinas de usinas hidrelétricas, devido à alta produção de biomassa dessas populações de plantas (Tanaka, 1998).

A infestação elevada nos reservatórios de usinas hidrelétricas por plantas aquáticas que apresentam alta capacidade de propagação e de produção de biomassa gera uma situação em que a necessidade de executar uma medida de controle torna-se indispensável; dentre as medidas de controle que podem ser tomadas, destaca-se o controle mecânico.

De acordo com Velini (1998), as operações relacionadas ao controle mecânico podem ser divididas em quatro etapas: a retirada das plantas dos rios, canais ou lagos; o transporte das plantas ainda no corpo hídrico; a transferência desse material para o ambiente terrestre; e o transporte e descarte do material coletado. Contudo, quando se adota o manejo mecânico, um volume muito grande de material vegetal é retirado do reservatório, e o local de descarte desse material deve ser escolhido de maneira que danos ao meio ambiente sejam minimizados.

Vários pesquisadores evidenciam o efeito que as plantas aquáticas apresentam em reduzir a carga de nutrientes minerais dissolvidos na água. No entanto, dentre os nutrientes presentes em sistemas aquáticos, destaca-se o grupo dos metais pesados, que compreende 84 elementos químicos com densidade acima de $5 \mathrm{~g} \mathrm{~cm}^{-3}$; a contaminação do ambiente por metais potencialmente tóxicos tem-se tornado preocupante, devido à utilização de grande variedade desses elementos pelo setor industrial (Corrêa et al., 2002; Moraes, 1999).

Jackson (1998) e Corrêa et al. (2002) alertam sobre a pouca informação referente às características químicas do material vegetal que é retirado de ambientes eutrofizados, bem como sobre a segurança ambiental na área de descarte, em relação à liberação de elementos tóxicos ao solo e lençol freático, no momento e após o descarte da biomassa.

Dessa forma, o objetivo do presente trabalho foi caracterizar a constituição química das quatro espécies de plantas aquáticas mais importantes, encontradas no reservatório da usina hidrelétrica de Salto Grande, em Americana-SP, de forma a fornecer subsídios para futuras avaliações sobre o comportamento da biomassa dessas espécies no local de descarte ou no próprio reservatório.

\section{MATERIAL E MÉTODOS}

As plantas aquáticas foram coletadas no reservatório de Salto Grande - formado pela barragem do Rio Atibaia, que está situada na bacia hidrográfica do Rio Piracicaba -, localizado no município de Americana-SP, a uma altitude de $530 \mathrm{~m}$. As espécies estudadas foram: Brachiaria arrecta, Eichhornia crassipes, Pistia stratiotes e Salvinia auriculata. As plantas foram amostradas aleatoriamente em três pontos no reservatório, utilizando-se um quadro metálico de $1 \mathrm{~m}^{2}$ de área, sendo em seguida colocadas em sacos plásticos, para facilitar o transporte. No laboratório, as espécies foram lavadas e, em seguida, após breve secagem para a retirada do excesso de água, acondicionadas em sacos de papel e colocadas em estufa de circulação forçada de ar a uma temperatura de $60 \stackrel{\circ}{ } \mathrm{C}$, até que atingissem peso constante; posteriormente, elas foram pesadas em balança de precisão, moídas em micromoinho e encaminhadas para análise dos elementos químicos.

A determinação dos elementos químicos foi realizada no laboratório de relação solo-planta do Departamento de Produção Vegetal, Setor Agricultura, da FCA-Unesp/Botucatu-SP. A análise do $\mathrm{N}$ foi efetuada segundo metodologia do semimicro Kjeldahl - digestão por ácido sulfúrico seguida por destilação e titulação. Para determinação dos teores dos demais elementos, o material foi digerido com uma mistura de ácido nítrico-perclórico, de acordo com a metodologia proposta por Malavolta et al. (1997). As amostras digeridas foram submetidas à espectrometria de plasma para determinação das concentrações de $\mathrm{P}, \mathrm{K}, \mathrm{Ca}$, 
Mg, S, Al, Na, Cu, Zn, Mn, Fe, B, Ba, Co, Mo, $\mathrm{Si}, \mathrm{Ag}, \mathrm{As}, \mathrm{Cd}, \mathrm{Cr}, \mathrm{Hg}, \mathrm{Li}, \mathrm{Ni}, \mathrm{Se}, \mathrm{Sn}, \mathrm{Pb}$ e V, de acordo com as soluções-padrão preestabelecidas no laboratório. Os valores obtidos pelo aparelho foram corrigidos de acordo com as concentrações utilizadas na digestão e a solução em branco, obtendo-se, dessa forma, os teores finais de cada elemento presente nas amostras. Na análise do teor de caborno foi utilizado o método para a determinação da matéria orgânica no solo, proposto por Allison (1965).

\section{RESULTADOS E DISCUSSÃO}

Os resultados referentes a produção de matéria seca, teores dos macronutrientes, carbono e relação $\mathrm{C} / \mathrm{N}$ das plantas aquáticas encontradas no reservatório de Salto Grande (Americana-SP) estão apresentados na Tabela 1, e aqueles referentes aos teores dos micronutrientes e dos elementos metálicos encontrados na matéria seca das plantas aquáticas, nas Tabelas 2 e 3, respectivamente.

Observa-se na Tabela 1 que a espécie B. arrecta apresentou a maior média de produção de matéria seca $\left(13,29\right.$ t ha $\left.^{-1}\right)$, enquanto as espécies S. auriculata, P. stratiotes e E. crassipes apresentaram produção média de
1,39; 4,41; e 5,17 $\mathrm{t} \mathrm{ha}^{-1}$ de matéria seca, respectivamente. Moraes (1999), analisando plantas aquáticas no mesmo reservatório, obteve valores próximos de produção de matéria seca para as espécies $P$. stratiotes e $B$. arrecta, exceto para E. crassipes, cujo valor foi 2,65 vezes superior ao obtido no presente trabalho. As médias dos teores de nitrogênio e fósforo foram mais elevadas na espécie $S$. auriculata e mais baixas na espécie $B$. arrecta. Contudo, as espécies E. crassipes e $P$. stratiotes apresentaram os maiores teores médios de potássio, cálcio e magnésio, com valores em torno de 28,09-30,36; 11,55-22,35; e 2,93-4,50 $\mathrm{g} \mathrm{kg}^{-1}$ da matéria seca, respectivamente. Os teores médios de enxofre e de alumínio não apresentaram grande variação entre as espécies, com exceção de $B$. arrecta, que apresentou um teor 5,5 vezes menor de alumínio em relação à média das demais espécies estudadas. Para o elemento sódio, os maiores valores foram obtidos pelas espécies S. auriculata e $P$. stratiotes, com 11,01 e $13,26 \mathrm{~g} \mathrm{~kg}^{-1}$ da matéria seca, respectivamente. Como os teores de nitrogênio foram mais baixos para a espécie $B$. arrecta e os teores de carbono mais elevados, esta espécie apresentou relação $\mathrm{C} / \mathrm{N}$ mais alta, em comparação com as demais espécies avaliadas.

Tabela 1 - Produção de matéria seca, teores dos macronutrientes, carbono e relação C/N das plantas aquáticas encontradas no reservatório de Salto Grande (Americana-SP). Coleta realizada em 16.4.2002

\begin{tabular}{|c|c|c|c|c|c|c|c|c|c|c|c|c|}
\hline \multirow{2}{*}{ Espécie } & \multirow{2}{*}{ Repetição } & M.S. & $\mathrm{N}$ & $\mathrm{P}$ & $\mathrm{K}$ & $\mathrm{Ca}$ & $\mathrm{Mg}$ & $\mathrm{S}$ & $\mathrm{Al}$ & $\mathrm{Na}$ & \multirow{2}{*}{$\frac{\mathrm{C}}{(\%)}$} & \multirow{2}{*}{$\mathrm{C} / \mathrm{N}$} \\
\hline & & $\left(\mathrm{t} \mathrm{ha}^{-1}\right)$ & \multicolumn{8}{|c|}{$\left(\mathrm{g} \mathrm{kg}^{-1}\right)$} & & \\
\hline \multirow{4}{*}{ Brachiaria arrecta } & 1 & 13,60 & 15,26 & 1,45 & 25,34 & 1,83 & 1,10 & 3,71 & 0,17 & 3,33 & 40,57 & 2,66 \\
\hline & 2 & 8,80 & 14,70 & 1,65 & 23,92 & 2,30 & 1,03 & 2,08 & 1,31 & 3,49 & 40,27 & 2,74 \\
\hline & 3 & 17,46 & 9,66 & 0,85 & 14,21 & 1,53 & 0,78 & 3,30 & 0,40 & 2,91 & 41,45 & 4,29 \\
\hline & Média & 13,29 & 13,21 & 1,32 & 21,16 & 1,89 & 0,97 & 3,03 & 0,62 & 3,24 & 40,76 & 3,23 \\
\hline \multirow{4}{*}{ Eichhornia crassipes } & 1 & 6,00 & 21,80 & 2,89 & 34,26 & 13,41 & 3,17 & 3,08 & 1,45 & 3,82 & 30,06 & 1,38 \\
\hline & 2 & 4,10 & 17,78 & 1,88 & 26,08 & 11,39 & 2,81 & 1,99 & 1,54 & 4,51 & 33,02 & 1,86 \\
\hline & 3 & 5,42 & 14,70 & 1,97 & 23,92 & 9,86 & 2,80 & 4,00 & 9,48 & 4,47 & 29,17 & 1,98 \\
\hline & Média & 5,17 & 18,09 & 2,25 & 28,09 & 11,55 & 2,93 & 3,02 & 4,15 & 4,27 & 30,75 & 1,74 \\
\hline \multirow{4}{*}{ Pistia stratiotes } & 1 & 4,40 & 25,76 & 4,00 & 29,20 & 19,72 & 4,11 & 2,78 & 2,77 & 12,30 & 28,58 & 1,11 \\
\hline & 2 & 4,20 & 21,14 & 3,04 & 26,60 & 24,72 & 4,88 & 6,38 & 2,90 & 14,10 & 26,81 & 1,27 \\
\hline & 3 & 4,64 & 21,14 & 3,42 & 35,28 & 22,62 & 4,49 & 2,80 & 3,12 & 13,37 & 28,58 & 1,35 \\
\hline & Média & 4,41 & 22,68 & 3,48 & 30,36 & 22,35 & 4,50 & 3,99 & 2,93 & 13,26 & 27,99 & 1,24 \\
\hline \multirow{4}{*}{ Salvinia auriculata } & 1 & 0,90 & 29,26 & 4,42 & 27,28 & 9,70 & 2,58 & 3,35 & 4,69 & 10,79 & 32,58 & 1,11 \\
\hline & 2 & 1,80 & 28,28 & 4,40 & 17,75 & 9,20 & 2,81 & 7,17 & 1,55 & 10,93 & 29,62 & 1,05 \\
\hline & 3 & 1,48 & 19,60 & 3,33 & 20,06 & 8,64 & 2,04 & 2,69 & 3,20 & 11,32 & 31,10 & 1,59 \\
\hline & Média & 1,39 & 25,71 & 4,05 & 21,70 & 9,18 & 2,48 & 4,40 & 3,15 & 11,01 & 31,10 & 1,25 \\
\hline
\end{tabular}


Tabela 2 - Teores dos micronutrientes da matéria seca das plantas aquáticas encontradas no reservatório de Salto Grande

(Americana-SP). Coleta realizada em 16.4.2002

\begin{tabular}{|c|c|c|c|c|c|c|c|c|c|c|}
\hline \multirow{2}{*}{ Espécie } & \multirow{2}{*}{ Repetição } & $\mathrm{Cu}$ & $\mathrm{Zn}$ & $\mathrm{Mn}$ & $\mathrm{Fe}$ & $\mathrm{B}$ & $\mathrm{Ba}$ & Co & Mo & $\mathrm{Si}$ \\
\hline & & \multicolumn{9}{|c|}{$\left(\mathrm{mg} \mathrm{kg}^{-1}\right)$} \\
\hline \multirow{4}{*}{ Brachiaria arrecta } & 1 & 5,22 & 210,00 & 54,00 & 360,00 & 62,00 & 22,00 & 1,18 & 0,00 & 2,62 \\
\hline & 2 & 6,56 & 237,80 & 155,00 & 1689,00 & 54,00 & 38,00 & 3,14 & 0,00 & 4,72 \\
\hline & 3 & 5,10 & 232,60 & 31,00 & 590,20 & 66,00 & 16,00 & 1,66 & 0,00 & 2,82 \\
\hline & Média & 5,63 & 226,80 & 80,00 & 879,73 & 60,67 & 25,33 & 1,99 & 0,00 & 3,39 \\
\hline \multirow{4}{*}{ Eichhornia crassipes } & 1 & 8,98 & 172,26 & 1254,00 & 2215,00 & 64,00 & 294,00 & 7,42 & 0,00 & 3,70 \\
\hline & 2 & 8,44 & 172,34 & 366,00 & 2391,00 & 56,00 & 220,00 & 2,06 & 0,00 & 6,50 \\
\hline & 3 & 11,82 & 216,40 & 728,00 & 9408,00 & 68,00 & 242,00 & 6,58 & 0,00 & 74,00 \\
\hline & Média & 9,75 & 187,00 & 782,67 & 4671,33 & 62,67 & 252,00 & 5,35 & 0,00 & 28,07 \\
\hline \multirow{4}{*}{ Pistia stratiotes } & 1 & 7,54 & 230,80 & 1319,00 & 3884,00 & 82,00 & 376,00 & 10,42 & 0,00 & 7,06 \\
\hline & 2 & 8,50 & 222,40 & 371,00 & 4032,00 & 108,00 & 456,00 & 2,96 & 0,00 & 4,50 \\
\hline & 3 & 9,70 & 246,60 & 928,00 & 4234,00 & 112,00 & 430,00 & 9,82 & 0,00 & 14,66 \\
\hline & Média & 8,58 & 233,27 & 872,67 & 4050,00 & 100,67 & 420,67 & 7,73 & 0,00 & 8,74 \\
\hline \multirow{4}{*}{ Salvinia auriculata } & 1 & 11,88 & 256,40 & 1491,00 & 2240,00 & 88,00 & 402,00 & 8,96 & 0,00 & 9,44 \\
\hline & 2 & 10,14 & 243,20 & 501,00 & 3878,00 & 90,00 & 220,00 & 3,66 & 0,00 & 5,68 \\
\hline & 3 & 11,40 & 251,40 & 1320,00 & 3500,00 & 130,00 & 328,00 & 4,20 & 0,00 & 6,80 \\
\hline & Média & 11,14 & 250,33 & 1104,00 & 3206,00 & 102,67 & 316,67 & 5,61 & 0,00 & 7,31 \\
\hline
\end{tabular}

Tabela 3 - Teores dos elementos metálicos da matéria seca das plantas aquáticas encontradas no reservatório de Salto Grande (Americana-SP). Coleta realizada em 16.4.2002

\begin{tabular}{|c|c|c|c|c|c|c|c|c|c|c|c|}
\hline \multirow{2}{*}{ Espécie } & \multirow{2}{*}{ Repetição } & $\mathrm{Ag}$ & As & $\mathrm{Cr}$ & $\mathrm{Hg}$ & $\mathrm{Li}$ & $\mathrm{Ni}$ & $\mathrm{Se}$ & Sn & $\mathrm{Pb}$ & $\mathrm{V}$ \\
\hline & & \multicolumn{10}{|c|}{$\left(\mathrm{mg} \mathrm{kg}^{-1}\right)$} \\
\hline \multirow{4}{*}{ Brachiaria arrecta } & 1 & 0,00 & 0,80 & 73,20 & 0,00 & 0,16 & 86,86 & 0,00 & 284,60 & 0,00 & 0,00 \\
\hline & 2 & 0,00 & 1,80 & 85,60 & 0,00 & 2,74 & 99,20 & 0,00 & 54,60 & 0,00 & 0,00 \\
\hline & 3 & 0,00 & 1,40 & 85,80 & 0,00 & 0,98 & 97,80 & 0,00 & 100,00 & 0,00 & 0,00 \\
\hline & Média & 0,00 & 1,33 & 81,53 & 0,00 & 1,29 & 94,62 & 0,00 & 146,40 & 0,00 & 0,00 \\
\hline \multirow{4}{*}{ Eichhornia crassipes } & 1 & 0,00 & 2,81 & 64,32 & 0,00 & 2,00 & 79,96 & 0,00 & 10,40 & 0,00 & 9,20 \\
\hline & 2 & 0,00 & 2,80 & 78,16 & 0,00 & 2,90 & 86,74 & 0,00 & 9,20 & 0,00 & 16,18 \\
\hline & 3 & 0,00 & 5,60 & 86,08 & 0,00 & 12,48 & 97,56 & 0,00 & 16,20 & 0,00 & 47,60 \\
\hline & Média & 0,00 & 3,74 & 76,19 & 0,00 & 5,79 & 88,09 & 0,00 & 11,93 & 0,00 & 24,33 \\
\hline \multirow{4}{*}{ Pistia stratiotes } & 1 & 0,00 & 4,00 & 82,20 & 0,00 & 4,56 & 100,02 & 0,00 & 67,56 & 0,00 & 15,52 \\
\hline & 2 & 0,00 & 0,12 & 77,14 & 0,00 & 3,42 & 98,42 & 0,00 & 95,94 & 0,00 & 9,08 \\
\hline & 3 & 0,00 & 0,12 & 87,56 & 0,00 & 3,12 & 108,46 & 0,00 & 34,22 & 0,00 & 6,48 \\
\hline & Média & 0,00 & 1,41 & 82,30 & 0,00 & 3,70 & 102,30 & 0,00 & 65,91 & 0,00 & 10,36 \\
\hline \multirow{4}{*}{ Salvinia auriculata } & 1 & 0,00 & 2,30 & 87,40 & 0,00 & 0,40 & 103,40 & 0,00 & 85,80 & 0,00 & 0,00 \\
\hline & 2 & 0,00 & 4,82 & 88,80 & 0,00 & 1,48 & 100,40 & 0,00 & 62,00 & 0,00 & 0,00 \\
\hline & 3 & 0,00 & 2,80 & 79,00 & 0,00 & 5,12 & 99,20 & 0,00 & 70,80 & 0,00 & 0,00 \\
\hline & Média & 0,00 & 3,31 & 85,07 & 0,00 & 2,33 & 101,00 & 0,00 & 72,87 & 0,00 & 0,00 \\
\hline
\end{tabular}

Quando se analisam os teores dos micronutrientes da matéria seca das plantas aquáticas (Tabela 2), pode-se observar que entre as espécies $P$. stratiotes, E. crassipes e $S$. auriculata os teores médios de cobre foram os mais altos, ao passo que, para os teores médios de zinco, as espécies $B$. arrecta, $P$. stratiotes e S. auriculata foram as que obtiveram os valores mais elevados. Com relação aos elementos manganês e ferro, $B$. arrecta apresentou os teores médios mais baixos, com cerca de 80,00 e $879,73 \mathrm{mg} \mathrm{kg}^{-1}$ da matéria seca, respectivamente. A média obtida do teor de manganês da matéria seca da espécie $B$. arrecta 
encontra-se abaixo dos níveis médios de manganês encontrados em gramíneas, em torno de $51 \mathrm{ppm}$ (Underwood, 1969, citado por Souza et al. 1999). Contudo, os teores de zinco, manganês e ferro encontrados na matéria seca das plantas aquáticas avaliadas foram, em geral, mais elevados do que os teores da matéria seca de algumas monocotiledôneas e dicotiledôneas terrestres, estudadas por Souza et al. (1999). Dentre as plantas aquáticas estudadas, os teores médios mais baixos do elemento boro foram obtidos nas espécies $B$. arrecta e E. crassipes, e os mais elevados, nas espécies $P$. stratiotes e $S$. auriculata. Analisando-se os teores médios de cobalto e bário, B. arrecta foi a espécie que apresentou os valores mais baixos, com cerca de 1,99 e $25,33 \mathrm{mg} \mathrm{kg}^{-1}$ da matéria seca, respectivamente. E. crassipes foi a espécie que obteve o maior valor médio de silício em relação às demais espécies avaliadas, com teor de $28,07 \mathrm{mg} \mathrm{kg}^{-1}$ da matéria seca. Nenhuma das plantas analisadas forneceu leitura para o elemento molibdênio quando as amostras foram submetidas à espectrometria de plasma.

Observando os dados da Tabela 3, nota-se que os teores médios de arsênio foram mais elevados nas espécies $S$. auriculata e E. crassipes; não ocorreu grande variação nos teores médios de cromo e de níquel dentre as quatro plantas estudadas. Houve menor presença do elemento lítio na espécie $B$. arrecta (1,29 $\left.\mathrm{mg} \mathrm{kg}^{-1} \mathrm{da} \mathrm{MS}\right)$ - esta espécie apresentou o maior teor médio do elemento estânio (146,40 $\mathrm{mg} \mathrm{kg}^{-1}$ da matéria seca).

Os valores referentes aos teores médios de lítio, níquel, cromo e estânio da matéria seca das plantas aquáticas analisadas foram, respectivamente, 3,$18 ; 3,78 ; 21,78$; e 77,37 vezes mais elevados do que os obtidos por Corrêa et al. (2002), ao analisarem os teores médios desses elementos nas plantas aquáticas imersas Egeria densa, Egeria najas e Ceratophyllum demersum, no verão de 2001. As espécies E. crassipes, P. stratiotes e $S$. auriculata não forneceram leitura para o elemento selênio quando as amostras foram submetidas à espectrometria de plasma. Somente as espécies $P$. stratiotes e E. crassipes apresentaram leitura para o elemento vanádio, com valores médios na ordem de 10,36 e $24,33 \mathrm{mg} \mathrm{kg}^{-1}$ da matéria seca, respectivamente. Não foi detectada, em nenhuma das plantas aquáticas estudadas, a presença dos elementos prata, chumbo e mercúrio.

\section{LITERATURA CITADA}

ALLISON, L. E. Organic carbon. In: BLACK, C. A. et al. (Eds.). Methods of soil analysis. ASA Madison: American Society of Agronomy, 1965. p. 1367-1379. (Agronomy Series, 9)

CORRÊA, M. R.; VELINI, E. D.; ARRUDA, D. P. Teores de metais na biomassa de Egeria densa, Egeria najas e Ceratophyllum demersum. Planta daninha, v. 20, p. 45-49, 2002. Edição Especial

JACKSON, L. J. Paradigms of metal accumulation in rooted aquatic vascular plants. Sci. Total Environ., v. 219, p. 223-231, 1998.

MALAVOLTA, E.; VITTI, G. C.; OLIVEIRA, S. A. Avaliação do estado nutricional das plantas: Princípios e Aplicações. 2.ed. Piracicaba: POTAFOS - Associação Brasileira para Pesquisa da Potassa e do Fosfato, 1997. $317 \mathrm{p}$.

MORAES, A. R. Estimativa de estoque de elementos químicos em macrófitas aquáticas do reservatório de Salto Grande (Americana-SP). 1999. 94 f. Dissertação (Mestrado em Ciências da Engenharia Ambiental) Universidade de São Paulo, São Carlos, 1999.

SOUZA, L. S. et al. Teores de macro e micronutrientes e a relação $\mathrm{C} / \mathrm{N}$ de várias espécies de plantas daninhas. Planta Daninha, v. 17, n. 1, p. 163-167, 1999. (Nota Científica)

TANAKA, R. H. Prejuízos provocados pelas plantas aquáticas. In: WORKSHOP CONTROLE DE PLANTAS AQUÁTICAS, 1998, Brasília-DF. Resumos... Brasília: IBAMA, 1998. p. 36-38.

THOMAZ, S. M. Fatores ecológicos associados à colonização e ao desenvolvimento de macrófitas aquáticas e desafios de manejo. Planta Daninha, v. 20, p. 21-33, 2002. Edição Especial.

VELINI, E. D. Controle mecânico de plantas aquáticas no Brasil. In: WORKSHOP CONTROLE DE PLANTAS AQUÁTICAS, 1998, Brasília-DF. Resumos... Brasília: IBAMA, 1998. p. 32-35. 